\title{
The Relationship Between Body Image and Sexual Function in Middle-Aged Women
}

\author{
Poorandokht Afshari ${ }^{1}$, Zeinab Houshyar ${ }^{2}$, Nahid Javadifar ${ }^{3}$, Fatemeh Pourmotahari ${ }^{4}$, Maryam Jorfi ${ }^{5}$
}

${ }^{1}$ M.Sc. of Midwifery, Assistant Professor, Menopause Andropause Research Center, Faculty of Nursing and Midwifery, Ahvaz Jundishapur University of Medical Sciences, Ahvaz, Iran

${ }^{2}$ M.Sc. of Midwifery, Lecture in Midwifery, Department of Research, Faculty of Nursing, Torbat Jam Faculty of Medical Sciences, Torbat Jam, Iran

${ }^{3}$ Ph.D. of Reproductive Health, Assistant Professor, Reproductive Health Promotion Research Center, Department of Midwifery, Faculty of Nursing and Midwifery, Ahvaz Jundishapur, University Of Medical Sciences, Ahvaz, Iran ${ }^{4}$ M.Sc. of Biostatistics, Department of Biostatistics Sciences, Dezful University of Medical Sciences, Dezful, Iran

${ }^{5}$ M.Sc. of midwifery, Lecture in Midwifery, Menopause Andropause Research Center, Faculty of Nursing and Midwifery, Ahvaz Jundishapur, University Of Medical Sciences, Ahvaz, Iran

\section{Type of article: Original}

\begin{abstract}
Introduction: An individual's social and marital function, interpersonal relationships, and quality of life may, sometimes be affected by negative body image. This study is aimed at determining the relationship between body image and sexual function in middle-aged women.

Methods: In this cross-sectional study, 437 middle-aged women, who were referred to various public healthcare centers in Ahvaz, Iran during 2014-2015, were selected. The Female Sexual Function Index (FSFI) and Body Shape Questionnaire (BSQ) were used for data collection. Chi-square, one-way analysis of variance, Spearman's correlation test, and logistic regression analysis were performed for statistical analysis.

Results: Approximately 58\% of the participants expressed satisfaction with their body image, $35 \%$ were mildly dissatisfied, and $7 \%$ were moderately dissatisfied with their body image. Body image had a significant negative relationship with sexual satisfaction and sexual function $(\mathrm{p}=0.005)$. Furthermore, there was a significant relationship between body image and sexual desire $(\mathrm{p}=0.022)$, pain $(\mathrm{p}=0.001)$, sexual arousal $(\mathrm{p}<0.0005)$, sexual orgasm ( $\mathrm{p}=0.001)$, and sexual satisfaction $(\mathrm{p}<0.0005)$.

Conclusion: As the results indicated, body image is an important aspect of sexual health. In this study, women with a positive body image had higher sexual function valuation, compared to women with a negative body image. Also, body shape satisfaction was a predictor of sexual function.

Keywords: Body image, Sexual function, Middle-aged women
\end{abstract}

\section{Introduction}

Middle age can be defined as the third quarter of the average life span. There are an estimated 3.5 million middle aged women in Iran.; this number is growing due to the increased life expectancy among women (2). Due to advances in medical care, about $95 \%$ of women reach the age of menopause in their middle age (3). Hot flashes, night sweats, and vaginal/urinary symptoms are the physical symptoms of menopause. In addition to the physical symptoms, irritability, mood disorders, anxiety, stress, low self-esteem, emotional instability, and slow memory are among the psychological symptoms of menopause. These disorders can have negative impacts on the physical, psychological, and sexual health of women (4). As a number of previous studies have indicated, sexuality has an undeniable impact on marital satisfaction (5-7). Furthermore, quality of life is lower in menopausal women due to the high prevalence of sexual dysfunction (2). In a previous study, the frequency of sexual dysfunction was $38.5 \%$ and $72.4 \%$ among premenopausal and postmenopausal women, respectively (8). Also, the prevalence of sexual

\section{Corresponding author:}

Houshyar Zeinab, Department of Research, Faculty of Nursing, Torbat Jam Faculty of Medical Sciences, Torbat Jam, Iran. Tel: +98.5152535558, Email: houshyarz1@mums.ac.ir

Received: May 26, 2016, Accepted: August 02, 2016, Published: November 2016

iThenticate screening: July 25, 2016, English editing: September 18, 2016, Quality control: September 27, 2016

(C) 2016 The Authors. This is an open access article under the terms of the Creative Commons Attribution-NonCommercialNoDerivs License, which permits use and distribution in any medium, provided the original work is properly cited, the use is non-commercial and no modifications or adaptations are made. 
dysfunction among Iranian women has been estimated at 31.5\% (9). Based on the literature, the prevalence of sexual arousal, lubrication, orgasm, and pain disorders was $66.4 \%, 38 \%, 34.8 \%$, and $38.4 \%$, respectively among Iranian women (10). Although physical factors (particularly low levels of hormones such as estrogen) play an important role in sexual dysfunction among middle-aged women, the significance of psychological factors cannot be ignored. Factors such as depression, anxiety, psychotic symptoms, low self-esteem, negative body image, and low sexual activity are the primary psychological symptoms of menopaus. Body image is an individual's perception of the aesthetics or sexual attractiveness of his/her body. Body image, which is related to an individual's perception of his/her body, includes beliefs, thoughts, and feelings about physical appearanc. In fact, there is a relationship between depression and negative body image. An individual's social and marital function, interpersonal relationships, and quality of life can be affected by negative body image (11). Middle age is associated with high psychosocial functioning, major changes in life (such as the loss of a supportive relationship), biological changes, negative attitudes towards menopause, uncertainty regarding one's future, and depression. Therefore, maintaining a high quality of life is relatively difficult during this period $(12,13)$. Unfortunately, there is insufficient data regarding body image and its impact on life among postmenopausal women. Therefore, in this study, we aimed to determine the relationship between body image and sexual function in middle-aged women.

\section{Material and Methods}

\subsection{Setting}

In this cross-sectional study, 437 middle-aged women, who were referred to public healthcare centers of Ahvaz, Iran during 2014-2015, were selected through simple random sampling. Considering the scarcity of similar research, a pilot study was performed on 67 qualified women; the sample size was calculated at 437 cases.

\subsection{Inclusion and exclusion criteria}

Literate, married women, who were sexually active, were recruited in this study. The age range of the subjects was 45-60 years. The exclusion criteria were as follows: 1) prior history of surgical interventions, e.g., hysterectomy and mastectomy; 2) depression or other mental disorders; 3) polygamy; 4) having a partner with a mental illness or sexual disorder; 5) chronic diseases such as cardiovascular diseases, diabetes, and asthma; 6) history of infertility and use of medications affecting sexual activity; and 7) obesity (body mass index $\geqslant 30 \mathrm{~kg} / \mathrm{m}^{2}$ ) or malnourishment (body mass index $\leqslant 18.5 \mathrm{~kg} / \mathrm{m}^{2}$ ).

\subsection{Data collection tools}

In this study, a demographic questionnaire, consisting of two sections, was applied. The first part included demographic information, while the second part was related to sexual matters. The reliability and validity of this questionnaire have been assessed by Zolfaghari and Zargar Shoushtari (13). In addition, Female Sexual Function Index (FSFI) and Body Shape Questionnaire (BSQ) were used for data collection. FSFI is a multi-dimensional, selfreport instrument for evaluating one's satisfaction with his/her sexual relationships. It is composed of 19 items, assessing six domains of sexual function in women, i.e., sexual desire, arousal, lubrication, orgasm, sexual satisfaction, and pain. The score of each domain is calculated by adding up the item valuation and multiplying the sum by the domain factor. The total FSFI score is calculated by determining the collective total of all six domains of sexual function, with higher valuation indicating better sexual function. The minimum and maximum valuations are 6 and 36, respectively. A total score below 26.55 represents sexual dysfunction. The validity and reliability of FSFI had been assessed by Fakhri et al. in 2008 (14). Also, according to a previous study by Mohammadi et al., satisfactory findings were reported with a Cronbach's alpha of 0.66 (or above) for sexually dysfunctional samples and a Cronbach's alpha of 0.70 (or above) for sexually active samples (15). BSQ is composed of 34 items, assessing one's body shape satisfaction and body shape preoccupations, particularly bulimia nervosa and anorexia nervosa over the past four weeks. To determine the outcome, a five-point Likert scale is applied, with valuation ranging between 34 and 170; higher valuations indicate greater dissatisfaction with body shape. The reliability and validity of this scale had been previously assessed by Zeyghami and colleagues (16).

\subsection{Framework and design}

In total, 10 public healthcare centers were selected through simple random sampling (five from each region) among 23 public healthcare centers in Ahvaz, Iran. The participants were randomly selected, based on their health record number. Middle-aged women who were eligible for the study (with an even record number) were selected and invited to participate in the study. Volunteers who failed to meet the inclusion criteria were excluded from the study and replaced. This process continued until we reached data saturation. Overall, 750 women were assessed based on the inclusion and exclusion criteria, among whom 500 cases were considered eligible. By reason of the majority of 
the participants being Arabs, a native assisted us with data collection. The demographic questionnaire, FSFI, and BSQ were completed by all the participants. Finally, 63 questionnaires remained incomplete and were removed from the study. Statistical analysis was performed on the data recorded in 437 questionnaires. One-way analysis of variance (ANOVA) and Chi-square tests were used to analyze the quantitative and qualitative data, respectively. Also, Spearman's rank correlation coefficient test and logistic regression analysis were used to assess the relationship between body image preoccupations and sexual function in women. Data were analyzed using SPSS Version 21 (IBMC Corp., Armonk, NY, USA). This study was approved by the Research Ethics Committee of Ahvaz Jundishapur University of Medical Sciences (code: ajumc.REC.1393.2204). Written informed consents were obtained from all the participants prior to data collection.

\section{Results}

\subsection{General findings}

According to the obtained results, $46 \%$ of the subjects had more than four children, while $54 \%$ had less than four children. Approximately $55 \%$ and $47 \%$ of women were in the postmenopausal and premenopausal stages, respectively. In $36 \%, 14 \%$, and $3 \%$ of postmenopausal women, 1-5, 6-10, and $>11$ years had passed since their menopause, respectively. The results showed that $22 \%, 11 \%, 9 \%$, and $3 \%$ of the subjects had used condoms, hormonal contraception, intrauterine devices, and tubal ligation for family planning, respectively. The demographic characteristics of the subjects and their partners are presented in Table 1. According to the BSQ results, 58\% of the participants were satisfied with their body image, 35\% were mildly dissatisfied, and 7\% were moderately dissatisfied. Among women with optimal sexual function, 74\%, 21\%, and 5\% were satisfied, mildly dissatisfied, and moderately dissatisfied with their body image, respectively. Also, among women with adequate sexual function, $55 \%$ were satisfied with their body image, $38 \%$ were mildly dissatisfied, and $7 \%$ were moderately dissatisfied with their body image. Overall, there was a significant relationship between body image and sexual function $(p=0.01)$.

Table1. Demographic characteristics of the participants and their partners

\begin{tabular}{|c|c|c|}
\hline \multicolumn{2}{|l|}{ Variables } & $\%$ \\
\hline \multirow[t]{3}{*}{ Age (year) } & $45-50$ & 50 \\
\hline & $51-55$ & 27 \\
\hline & $56-60$ & 23 \\
\hline \multirow[t]{3}{*}{ Age at marriage (year) } & $<20$ & 56 \\
\hline & $20-30$ & 38 \\
\hline & $>30$ & 6 \\
\hline \multirow[t]{3}{*}{ Educational level } & Primary level or lower & 17 \\
\hline & Secondary school & 67 \\
\hline & High school & 16 \\
\hline \multirow[t]{4}{*}{ Educational level of the partner } & Primary level or lower & 39 \\
\hline & Secondary school & 18 \\
\hline & High school & 27 \\
\hline & Academic education & 16 \\
\hline \multirow[t]{4}{*}{ Age difference between the partners (year) } & $\leq 5$ (older partner) & 54 \\
\hline & 5-10 (older partner) & 28 \\
\hline & $>11$ (older partner) & 6 \\
\hline & Woman older than the partner & 12 \\
\hline \multirow[t]{3}{*}{ Occupational status } & Housewife & 70 \\
\hline & Employee & 20 \\
\hline & self-employed & 10 \\
\hline \multirow[t]{4}{*}{ Occupational status of the partner } & Self-employed & 54 \\
\hline & Employee & 27 \\
\hline & Retired & 13 \\
\hline & Unemployed & 6 \\
\hline \multirow[t]{3}{*}{ Residential status } & Owner & 78 \\
\hline & Rental property & 19 \\
\hline & Living with the spouse's family & 3 \\
\hline \multirow[t]{2}{*}{ Income status } & Moderate & 93 \\
\hline & Poor & 7 \\
\hline
\end{tabular}




\subsection{The relationship between body image and domains of sexual function}

The mean and standard deviation of sexual function domains, based on women's perception of body image, are shown in Table 2. According to this table, there was a significant relationship between the subjects' sexual desire and their perception of body image $(\mathrm{p}=0.001)$. Also, there was a significant relationship between body image and sexual arousal $(p<0.0005$ (, sexual orgasm $(p=0.001)$, sexual satisfaction $(p<0.0005)$, and pain $(p<0.0005)$. However, there was no significant relationship between lubrication and women's perception of body image $(\mathrm{p}=0.31)$. The results showed a significant relationship between sexual arousal and sexual function $(\mathrm{r}=0.50, \mathrm{p}<0.0005)$.

Table 2. The mean and standard deviation of the domains of sexual function, based on the body image perception

\begin{tabular}{|l|l|l|l|l|}
\hline \multirow{2}{*}{ Domains of sexual function } & \multicolumn{2}{|l|}{ Perception of body image (Mean \pm SD) } & \multirow{2}{*}{-value } \\
\cline { 2 - 5 } & No concerns & Mild concerns & Moderate concerns & \\
\hline Desire & $3.41 \pm 1.02$ & $3.39 \pm 1.08$ & $2.64 \pm 0.99$ & 0.001 \\
\hline Arousal & $3.74 \pm 1.41$ & $3.42 \pm 1.49$ & $2.75 \pm 1.06$ & $<0.0005$ \\
\hline Lubrication & $3.42 \pm 1.27$ & $3.39 \pm 1.31$ & $3.42 \pm 1.27$ & 0.31 \\
\hline Orgasm & $3.64 \pm 1.36$ & $3.30 \pm 1.37$ & $2.82 \pm 1.03$ & 0.001 \\
\hline Satisfaction & $3.88 \pm 1.38$ & $3.55 \pm 1.19$ & $2.70 \pm 1.20$ & $<0.0005$ \\
\hline Pain & $3.86 \pm 1.10$ & $3.27 \pm 1.47$ & $3.96 \pm 1.10$ & $<0.0005$ \\
\hline Total & $21.98 \pm 6.79$ & $20.34 \pm 6.15$ & $17.93 \pm 5.44$ & 0.001 \\
\hline
\end{tabular}

\subsection{Confounding variables for women's perception of body image}

The confounding variables for women's perception of their body image are presented in Table 3. According to this table, Arab women were more likely to be satisfied with their body image, compared to others (OR=4.195, $\mathrm{CI}=0.637-27.636, \mathrm{p}=0.136$ ). With regard to a woman's occupational status, probability of body image satisfaction in employed women was 7.729 times higher than housewives $(\mathrm{OR}=7.729, \mathrm{CI}=1.308-45.68, \mathrm{p}=0.024)$. Also, probability of body image satisfaction in women whose partners were retired was 0.164 times greater than women whose partners were employed $(\mathrm{OR}=0.164, \mathrm{CI}=0.038-0.711, \mathrm{p}=0.016)$. In addition, probability of body image satisfaction in women with two or more unmarried children was 0.297 times higher than women who did not $(\mathrm{OR}=0.297$, $\mathrm{CI}=0.088-1.002, \mathrm{p}=0.05$ ). Finally, body image satisfaction in women who took the initiative in sexual interaction was significantly higher than women whose husbands took the initiative $(\mathrm{OR}=0.043, \mathrm{CI}=0.002-0.937, \mathrm{p}=0.045)$.

Table 3. The major confounding variables of women's perception of their body image, based on multivariate logistic regression test

\begin{tabular}{|l|l|l|l|l|}
\hline Confounding variables & B & p-value & OR \\
\hline Ethnicity (Fars) & Arab & -4.459 & $>0.0005$ & 0.012 \\
\cline { 2 - 5 } & Lur & -4.364 & $>0.0005$ & 0.013 \\
\cline { 2 - 5 } & Others & -3.006 & 0.003 & 0.049 \\
\hline \multirow{3}{*}{ Occupational status (Housewife) } & Self-employed & 2.045 & 0.024 & 7.729 \\
\cline { 2 - 5 } & Employee & 2.081 & 0.061 & 8.010 \\
\hline \multirow{3}{*}{ Partner's ethnicity (Fars) } & Arab & 1.434 & 0.136 & 4.195 \\
\cline { 2 - 5 } & Lur & 1.451 & 0.117 & 4.268 \\
\cline { 2 - 5 } & Others & 0.835 & 0.266 & 2.304 \\
\hline \multirow{3}{*}{ Partner's education (academic) } & Illiterate or primary level & 1.034 & 0.235 & 2.811 \\
\cline { 2 - 5 } & Secondary education & 0.733 & 0.378 & 2.167 \\
\cline { 2 - 5 } & High school & 1.067 & 0.169 & 2.907 \\
\hline Partner's occupational status (Employee) & Self-employed & 0.945 & 0.149 & 0.389 \\
\cline { 2 - 5 } & Unemployed & -1.125 & 0.267 & 0.325 \\
\cline { 2 - 5 } & Retired & -1.807 & 0.016 & 0.164 \\
\hline Number of children (four or less) & More than four & 0.678 & 0.173 & 1.971 \\
\hline Number of unmarried children & One & -0.096 & 0.897 & 0.909 \\
\cline { 2 - 5 } & Two or more & -1.215 & 0.05 & 0.297 \\
\hline Marital satisfaction & Somehow & -0.826 & 0.138 & 0.438 \\
\cline { 2 - 5 } & None & -0.096 & 0.922 & 0.908 \\
\hline Sexual initiative & Female & -3.155 & 0.045 & 0.043 \\
\cline { 2 - 5 } & Both & -0.0 .39 & 0.942 & 0.961 \\
\hline Attitude towards sex (pleasure) & Obligation & -0.915 & 0.418 & 0.401 \\
\cline { 2 - 5 } & Obligation \& pleasure & -1.147 & 0.292 & 0.318 \\
\cline { 2 - 5 } & Others & 0.594 & 0.697 & 1.812 \\
\hline
\end{tabular}




\section{Discussion}

This study was aimed at determining the relationship between body image preoccupations and sexual function in middle-aged women. According to our study, the majority of middle-aged women showed poor sexual activity. Moreover, women with a positive body image had higher sexual function valuation, compared to women with a negative body image. In the present study, there was a negative linear relationship between all six domains of sexual function and women's perception of body image. In other words, sexual desire, arousal, and orgasm improved as body image valuation increased. On the other hand, sexual function valuation decreased in women who were dissatisfied with their body shape. Various studies have emphasized on the role of body image in various aspects of sexual activity and sexual function. In line with our study, the relationship between women's body image, selfimage, and sexual behavior was assessed in a study by Ackard and colleagues. As the results indicated, sexual activity, sexual orgasm, and positive social interactions were more observed in women who were satisfied with their body image. Also, positive body image was associated with overall satisfaction, which was a predictor of sexual activity (17). Additionally, Pujols et al. showed a positive relationship between body image, sexual function, and sexual satisfaction. Weight concerns, physical conditions, sexual attraction, and preoccupations with physical appearance during sexual activity were the main factors contributing to sexual dissatisfaction. The study also found that different aspects of body image were strong predictors of sexual satisfaction in women (18). According to a previous study, negative body image and negative genital self-image were common among women with dyspareunia (8). Additionally, Davison et al. examined the relationship between various aspects of body image and sexual function in middle-aged individuals and showed a relationship between poor body image and problematic social and sexual functioning. Poor body image was also found to be associated with depression and anxiety symptoms (19). The results of these two discussed studies were in line with the present findings. Satinsky et al. performed a study to determine the relationship between body appreciation and sexual function, and assessed the impact of body size in women. According to their study, the majority of subjects reported body dissatisfaction, while the majority had high self-esteem. As the results indicated, women could overcome a negative body image by improving their self-esteem (20). In consistence with the findings reported by Satinsky et al., Albertson et al. showed that self-esteem could decrease body shape dissatisfaction. In fact, self-esteem had a strong association with psychological health and could discourage individuals from comparing themselves with others, based on physical appearance (21). In the present study, it was revealed that the chance of body image satisfaction was higher in Fars women, compared to Arabs, Lurs, and other ethnicities. Moreover, body image satisfaction was more prevalent among employed women, compared to housewives. Furthermore, women with employed partners were more satisfied with their body image, compared to those whose partners were retired. The findings also revealed, women with less than two unmarried children had a higher probability of body image satisfaction, compared to those with two or more unmarried children. Additionally, in our study, probability of body image satisfaction in women who took sexual initiative was lower than women whose husbands took the initiative. These results were confirmed by Ackard et al. (17) and Arman et al. (2). According to the study by Ackard et al., sexual initiative and positive social relations were more prevalent among women who were satisfied with their body. These women were willing to try new sexual activities and satisfy their partners (17). There is a significant positive correlation between body esteem and happiness; in other words, body image is a major contributor to overall life happiness; this correlation can be observed among women at any age (22). On the other hand, the correlation between depression and obesity, which strongly influences women's perception of their body, has been confirmed in multiple studies in middle-aged women (16). In fact, decreased physical activity and negative body image are the main mechanisms of the correlation between obesity and depression (11). According to a study by Moin et al., body image, sexual self-esteem, sexual satisfaction, and life satisfaction were lower in women with physical disability, compared to women with no physical disability, while sexual needs and desires of disabled women were similar to healthy women. In total, a significant positive correlation was observed between sexual satisfaction and happiness (23). Also, Khorshid et al. performed a study to investigate the body image of postmenopausal women. The body image of the majority of these women was generally positive and women with a good body image had more positive health behavior than other women. Also, there was no major difference between women undergoing hysterectomy (or reaching menopause) and others, in terms of body image perception (24). According to a study by Steer and Tiggemann, sexual satisfaction is a major predictor of sexual function (25). To the best of our knowledge, body image plays an important role in sexual practice and satisfaction. However, some studies have shown that the overall selfsatisfaction has a more significant impact on sexual behavior (17). As noted above, our findings were confirmed by the results reported by previous research. The relationship between women's perception of body image and sexual function is multifaceted. The concerns of people, particularly women, about how others may evaluate their body can significantly affect their sexual activity and quality of life. These concerns are affected by various social, cultural, and ethnic factors (5). 


\section{Study limitations}

Considering the design of the present study (cross-sectional research), one of the limitations was that causal relationships between the variables could not be evaluated. Also, Iranian women may feel too embarrassed to express their genuine feelings towards sex due to cultural barriers.

\section{Conclusions}

The present study showed that women with a positive body image had higher sexual function valuation, compared to those with a negative body image. Therefore, body shape satisfaction was a predictor of sexual function. Since body image is an important aspect of sexual health, our findings could help improve women's general health status. Further research is required to determine other effective factors for sexual health and to assess the effects of occupational status on body image, sexual performance, and sexual satisfaction. Moreover, future studies should focus on the effects of counseling on sexual satisfaction and sexual function in order to improve the body image of middle-aged women and assess the relationship between body image satisfaction, and sexual function in pre- and post-menopausal women.

\section{Acknowledgments:}

This study was extracted from a Master's thesis, approved by Ahvaz Jundishapur University of Medical Sciences. We would like to thank the Deputy of Research of the Department of Nursing, School of Nursing and Midwifery, Jundishapur University of Medical Sciences for the financial support and their cooperation with the present study.

\section{Conflict of Interest:}

There is no conflict of interest to be declared.

\section{Authors' contributions:}

All authors contributed to this project and article equally. All authors read and approved the final manuscript.

\section{References:}

1) Beigi M, Fahami F, Hassanzahraei R, Arman S. Associative factors to sexual dysfunction in menopause women. Iran J Nurs Midwifery Res. 2008; 13(1).

2) Arman S, Fahami F, Hasan Zahraee R. A comparative Study on women's sexual functioning disorders before and after menopause. Arak Med Univ J. 2006; 8(3): 1-7.

3) Slevec JH, Tiggemann M. Predictors of body dissatisfaction and disordered eating in middle-aged women. Clin Psychol Rev. 2011; 31(4): 515-24. doi: 10.1016/j.cpr.2010.12.002. PMID: 21239098.

4) Moghimian M, Salmani F, Azarbarzin M. Investigation of relationship between body image satisfaction and academic field of study of female students of islamic azad university branch of najafabad. Iranian journal of nursing research. 2012; 7(25): 64-71.

5) Asgari P, Shababi R. A comparison between the quality of life, life satisfaction, sex role attitude \& selfesteem among students with high and low body image. Andisheh va raftar (Applied psychology). 2010; 5(17): 9-18.

6) Dehghani M, Chehrzad M, Jafari AM,. Investigating the Relationship between Satisfaction from Body Image and Socio Cultural Patterns among Female Adolescents in Rasht City. Scientific Journal of Hamadan Nursing \& Midwifery Faculty. 2012; 20(3): 26-36.

7) Riahi ME. Gender differences in the level of body image satisfaction. Woman In Development And Politics. 2011; 9(3(34)): 5-33.

8) Pazmany E, Bergeron S, Van Oudenhove L, Verhaeghe J, Enzlin P. Body image and genital self-image in pre-menopausal women with dyspareunia. Arch Sex Behav. 2013; 42(6): 999-1010. doi: 10.1007/s10508013-0102-4. PMID: 23605571.

9) Safarinejad MR. Female sexual dysfunction in a population-based study in Iran: prevalence and associated risk factors. Int J Impot Res. 2006; 18(4): 382-95. doi: 10.1038/sj.ijir.3901440. PMID: 16395324.

10) Bagherzadeh R, Zahmatkeshan N, Gharibi $T$, Akaberian S, Mirzaei K, Kamali F, et al. Prevalence of female sexual dysfunction and related factors for under treatment in Bushehrian women of Iran. Sexual Disabil. 2010; 28(1): 39-49. doi: 10.1007/s11195-010-9149-5.

11) Simon GE, Ludman EJ, Linde JA, Operskalski BH, Ichikawa L, Rohde P, et al. Association between obesity and depression in middle-aged women. Gen Hosp Psychiatry. 2008; 30(1): 32-9. doi: 10.1016/j.genhosppsych.2007.09.001. PMID: 18164938, PMCID: PMC2675189. 
12) Sotoudeh G, Niyazi E, Khosravi Sh, Khajeh Nasiri F, Koohdani F. Prevalence and determinants of obesity and overweight in pre-and post-menopausal women in Islamshahr: a population-based study. Hayat. 2010; 16(2): 47-54.

13) Johnson KG. Serials-The Constant Midlife Crisis. Serial Rev. 2006; 32(1): 35-9. doi: 10.1016/j.serrev.2005.11.002.

14) Fakhri A, Pakpour AH, Burri A, Morshedi H, Zeidi IM. The Female Sexual Function Index: translation and validation of an Iranian version. J Sex Med. 2012; 9(2): 514-23. doi: 10.1111/j.1743-6109.2011.02553.x. PMID: 22146084.

15) Mohammadi KH, Heydari M, Faghihzadeh S. The female sexual function index (FSFI): validation of the Iranian version. Payesh. 2008; 7(3): 269-78.

16) Zeighami Mohammadi Sh, Mojdeh F. Correlation between body mass index, body image and depression among women referring to Health Clinic of Hazrat-e-Ali Hospital Health Clinic in Karaj (2009). Mod Care J. 2012; 9(1): 40-8.

17) Ackard DM, Kearney - Cooke A, Peterson CB. Effect of body image and self - image on women's sexual behaviors. Int J Eat Disord. 2000; 28(4): 422-9. PMID: 11054789.

18) Pujols Y, Seal BN, Meston CM. The association between sexual satisfaction and body image in women. J Sex Med. 2010; 7(2pt2): 905-16. doi: 10.1111/j.1743-6109.2009.01604.x. PMID: 19968771, PMCID: PMC2874628.

19) Davison TE, McCabe MP. Relationships between men's and women's body image and their psychological, social, and sexual functioning. Sex Roles. 2005; 52(7-8): 463-75. doi: 10.1007/s11199-005-3712-z.

20) Satinsky S, Reece M, Dennis B, Sanders S, Bardzell S. An assessment of body appreciation and its relationship to sexual function in women. Body Image. 2012; 9(1): 137-44. doi: 10.1016/j.bodyim.2011.09.007. PMID: 22018776.

21) Albertson ER, Neff KD, Dill-Shackleford KE. Self-compassion and body dissatisfaction in women: A randomized controlled trial of a brief meditation intervention. Mindfulness. 2015; 6(3): 444-54. doi: 10.1007/s12671-014-0277-3.

22) Stokes R, Frederick-Recascino C. Women's perceived body image: relations with personal happiness. J Women Aging. 2003; 15(1): 17-29. doi: 10.1300/J074v15n01-03. PMID: 12678183.

23) Moin V, Duvdevany I, Mazor D. Sexual identity, body image and life satisfaction among women with and without physical disability. Sexual Disabil. 2009; 27(2): 83-95. doi: 10.1007/s11195-009-9112-5.

24) Khorashadizadeh F, Karamidehkordi A, Rahsepar A, Latifnejad RR, Salari M, Esmaily H, et al. Determination of the association between body image with sexual function and marital adjustment in fertile and infertile women by path analysis modeling. Journal of north khorasan university of medical sciences. 2011; 3: 23-32.

25) Steer A, Tiggemann M. The role of self-objectification in women's sexual functioning. J Soci Clin Psychol. 2008; 27(3): 205-25. doi: 10.1521/jscp.2008.27.3.205. 